\title{
Adsorption of Acid Red 52 contained in waste water by co-products of the phosphate industry: Kinetics and thermodynamic
}

\author{
Samia Nasra,b,c, Samira Jebahid ${ }^{\mathrm{d}}$, Mustapha Hidouri ${ }^{\mathrm{e}}$, Khaled Boughzala ${ }^{\mathrm{a}, \mathrm{f}^{*}}$ \\ (a)Unité de recherche électrochimie matériaux et environnement, Ecole préparatoire des études \\ d'ingéniorat de Kairouan Avenue Assad ibn elfourat 3100 Kairouan. \\ (b) Advanced Functional Materials and Optoelectronic Laboratory (AFMOL), Departement of \\ physics, Faculty of Sciences, King Khalid University, P.O. Box 9004, ABHA, Saoudi Arabia

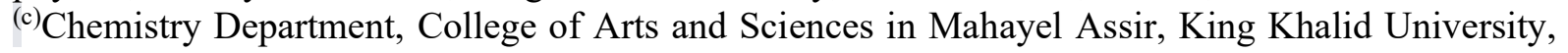 \\ Abha, Saudi Arabia. \\ (d)Energy and Matter Research Laboratory, National Center for Nuclear Sciences and Technology, \\ Sidi Thabet, Tunisia. \\ (e)High Institute of Applied Sciences and Technology, 6072 Zrig, Gabes University, Tunisia. \\ ${ }^{(f)}$ RU Analysis and applied process for Environment, High Institute for Applied Sciences and \\ technology, 5121 Mahdia, Tunisia.
}

\begin{abstract}
Water is essential for all living things however its pain has become serious. Many industrial activities cause its pollution by the release of polluting byproduct. Waste water treatment is hence necessary. In this context, the waste water of the textile industry containing Red Acid 52 was treated by the solid waste of the washed natural phosphate byproduct. Natural phosphate was also studied. The solid materials were first characterized by chemical analysis, Fourier Transform Infrared spectroscopy (FTIR) and X-ray diffraction (XRD). The phosphate materials were after that, tested in the adsorption of the Red Acid 52. The experimental data indicated that the phosphate waste rock allowed the removal of Red Acid 52. Its maximum retention capacity attained 18.4 mg.g ${ }^{-1}$. Calcinations of materials inhibits the removal capacity found reduced by 60 to $70 \%$. The adsorption kinetics of the Red Acid 52 on the material is well described by the pseudo second order model while the adsorption isotherms are identified by the Langmuir model. Hereafter, the thermodynamic study revealed that the adsorption process is spontaneous and exothermic.
\end{abstract}

Keywords: Waste water, Phosphate co-product, Adsorption, Red Acid 52.

\section{Introduction}

The activities of textile dyers are responsible for significant pollution of residual water. These water discharges, which are very loaded with synthetic dyes, usually exhibit a disturbing, intense coloring and high toxicity, especially when they are discharged directly into nature or into sewerage pipes. With the emergence of new standards and increasingly stringent environmental legislation, 
water discharges will imperatively require treatment to reduce or even eliminate their coloring and their pollutant load before being discharged into the nature.

The literature reports several techniques for the treatment and de-pollution of waste textile effluents. These include membrane filtration techniques [1], coagulation / flocculation [2], electrocoagulation [3], advanced oxidation techniques [4-6] and aerobic and anaerobic biological processes [7-9]. For economic and technical reasons, most of these techniques have not given satisfactory results. Moreover, adsorption is one of the most attractive remediation techniques in recent decades [2]. Although activated carbon remains the most effective adsorbent, its price, still considered high, prompts researchers to find other alternative and inexpensive materials. Most of these materials are natural [10-16] or from waste agriculture and other industries such as, for example, the food industry [17-21].

This last approach, which consists in recovering waste from various industries, by applying it in the decontamination of wastewater discharges, has become a very emerging ecological concept and very widespread in the world of scientific research, since it is part of the sustainable development framework.

Solid waste from the phosphate industry, which is found in abundance in Tunisia, is currently a national environmental problem. This is why; it seemed interesting to use them in the decontamination of wastewater discharges. Indeed, the literature only reveals the existence of a few studies relating to the adsorption of certain textile water discharges by phosphogypsum [22] or the adsorption of basic dyes and reactive dyes by natural phosphate [23, 24].

In this work, we interested on synthetic acid dyes, widely used in the dyeing of wool, silk, polyamide and even leathers and furs $[25,26]$. Among these dyes, we have chosen an azo dye, Red Acid 52.

\section{Materials and methods}

\subsection{Materials}

Phosphate waste rock is a byproduct of a phosphate company's washing plant. Prior to use, the samples have been considerably washed with distilled water and then dried in an oven at $105{ }^{\circ} \mathrm{C}$.

The phosphate waste rock was exposed to thermal activation under nitrogen $(150 \mathrm{~mL} / \mathrm{h})$ at the temperature of $1000^{\circ} \mathrm{C}$ at $5^{\circ} \mathrm{C} / \mathrm{min}$ for $2 \mathrm{~h}$.

In the following sections, the phosphate waste rock and the phosphate waste rock calcined will be assigned DS and DSC. Both compounds were intended for the removal tests of the Acid Red 52 dye. Red Acid 52 with a chemical structure developed in Figure 1. Its molar mass is 580.65 g.mol ${ }^{-1}$. 


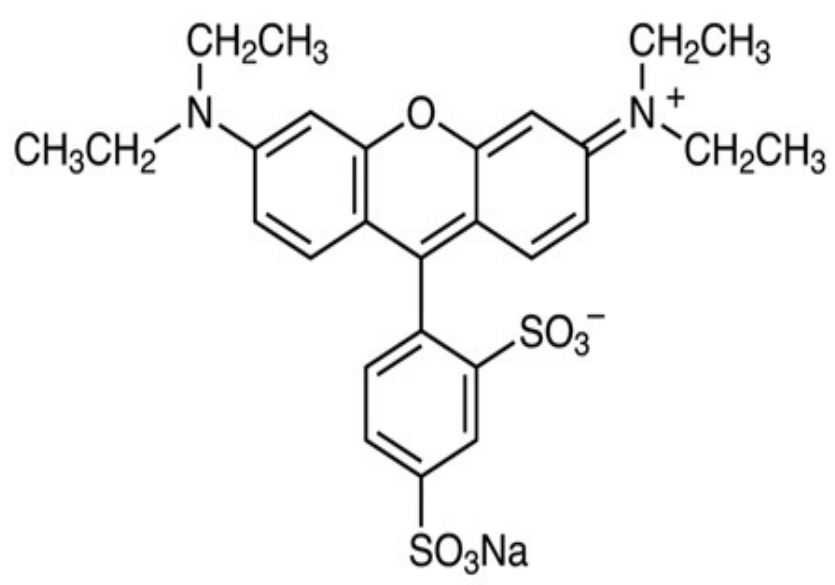

Figure 1. Chemical structure of Acid Red 52 dye

Its absorption spectrum is shown in Figure 2. According to this figure, its maximum absorbance, Amax, occurs for a wavelength, $\lambda$ max, equal to $568 \mathrm{~nm}$.

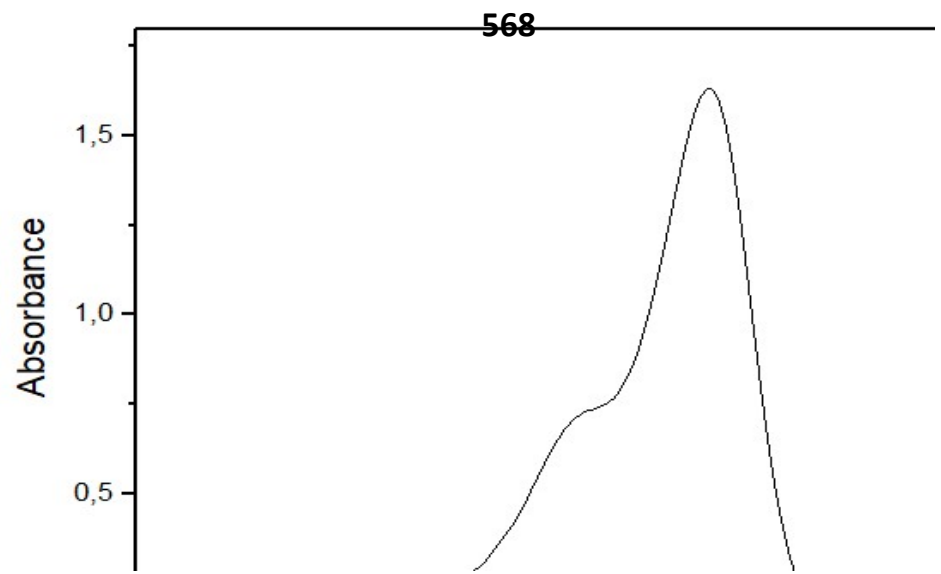

Figure 2. Visible spectrum of the Acid Red 52 dye studied.

\subsection{Removal experiments}

The absorption experiments were carried out in batch with different amounts of dyes and adsorbents. In addition to the effect of absorbent mass, we investigated the effect of $\mathrm{pH}$, dye concentration, contact time and temperature. Apart from the experiments studying the effect of temperature all the others were carried out at room temperature. After stirring at a given speed for a fixed period of time, samples were separated from the absorbent by centrifugation and measured by using UV-visible spectrophotometer type UV-2401PC, at a wavelength of $568 \mathrm{~nm}$. The residual dye concentration in each of the suspensions was determined using a previously established calibration curve. The amount of dye adsorbed on the surface of the powders at time $t$ is given by the following relationship and the percentage of discoloration by: 


$$
\begin{aligned}
& R(\%)=100 *\left(\frac{\left.C_{0}-C_{\mathrm{t}}\right)}{C_{\mathrm{D}}}\right. \\
& \mathrm{q}=\left(\mathrm{C}_{0}-\mathrm{C}_{\mathrm{t}}\right) \frac{\mathrm{V}}{\mathrm{m}}
\end{aligned}
$$

Where $\mathrm{C}_{0}$ and $\mathrm{C}_{\mathrm{e}}$ are respectively the initial and residual concentrations of the dye at time $\mathrm{t}$ (mg.L${ }^{1}$ ), $\mathrm{V}$ is the volume of the solution (L) and $\mathrm{m}$ is the mass of the adsorbent used (g).

The $\mathrm{pH}$ measurements were carried out using a BPH 213 type $\mathrm{pH}$ meter.

\subsection{Characterization}

The Chemical analysis of the adsorbents were carried out using an atomic absorption spectrometer type Perkin Elmer 3110. The DRX diffractograms were recorded using a PAnalytical X'Pert Pro type diffractometer, in the $2 \theta$ range $10-60^{\circ}$ with a step of $0.02^{\circ}$ and an equal counting time of $1 \mathrm{~s}$, using the $\mathrm{K}_{\alpha}$ radiation of copper $(\lambda=1.5406 \AA)$. The infrared absorption spectra, recorded using a Perki Elmer 1283 Fourrier transform spectrometer using a potassium bromide (KBr) method. Thermal gravimetric (TGA) and differential analysis (TDA) was performed using a Setaram Instrumentation SETSYS evolution system with a heating rate of $10{ }^{\circ} \mathrm{C} / \mathrm{min}$ up to $1000{ }^{\circ} \mathrm{C}$ under an air atmosphere. The surface morphology of the samples was examined by scanning electronic microscopy (SEM, FEI Quanta 200). The specific surface area (SSA) values were estimated from nitrogen adsorption isotherms using the BET (Brunauer-Emmett-Teller) equation. The isotherms were obtained using a Micromeritics ASAP 2020 system. The samples were outgassed at $120^{\circ} \mathrm{C}$ for $8 \mathrm{~h}$ prior to the measurement. The concentration of AR- 88 at equilibrium was determined during the removal runs using a UV-visible spectrophotometer (Perkin Elmer model LAMBDA20) at a maximum wavelength of $568 \mathrm{~nm}$.

\section{Results and discussion}

\section{1. Characterization of adsorbents}

The results of the chemical analysis, given in Table 1 showed that the concentration of $\mathrm{CaO}$ is equal to $26 \%$ in the DS sample. This sample has a $\mathrm{P}_{2} \mathrm{O}_{5}$ content of $14 \%$. A small percentage of $\mathrm{MgO}$, close to $0.87 \%$, was detected. The $\mathrm{Ca} / \mathrm{P}$ atomic ratio is approximately 1.91 for $\mathrm{DS}$. The $\mathrm{Cd}$ content was close to $45 \mathrm{ppm}$. The heat treatment did not radically change the chemical composition and a slight variation in $\mathrm{P}_{2} \mathrm{O}_{5}$ was observed as for other phosphate rocks [27]. 
Table 1. Chemical composition of adsorbants

\begin{tabular}{cccccc}
\hline$\downarrow$ Adsorbants & $\mathbf{\% P}_{\mathbf{2}} \mathbf{O}_{\mathbf{5}}$ & $\mathbf{\% C a O}$ & $\mathbf{\% M g O}$ & $\mathbf{C d}(\mathbf{p p m})$ & $\mathbf{C a O} / \mathbf{P}_{\mathbf{2}} \mathbf{O}_{\mathbf{5}}$ \\
\hline $\mathrm{DS}$ & 14 & 26,72 & 2,15 & 51 & 1,908 \\
\hline
\end{tabular}

The crystallographic identification of the DRX diagrams given in figure 3 reveals that the powder contained mainly as the major phase of carbonated fluorapatite $\left(\mathrm{Ca} 9.55\left(\mathrm{PO}_{4}\right)_{4.96} \mathrm{~F}_{1.96}\left(\mathrm{CO}_{3}\right)_{1.28}\right)$, with traces of heulandite $\left.\left.\left(\left(\mathrm{C}_{2} \mathrm{H}_{5}\right) \mathrm{NH}_{3}\right)_{7,85}\left(\mathrm{Al}_{8,7} \mathrm{Si}_{27,3}\right) \mathrm{O}_{72}\right)\left(\mathrm{H}_{2} \mathrm{O}\right)_{6,92}\right)$ and quartz $\left(\mathrm{SiO}_{2}\right)$. After calcination, at $1000{ }^{\circ} \mathrm{C}$, no variation of the major phase was observed. Also, it is noted that calcination improves the crystallinity of the sample [27].

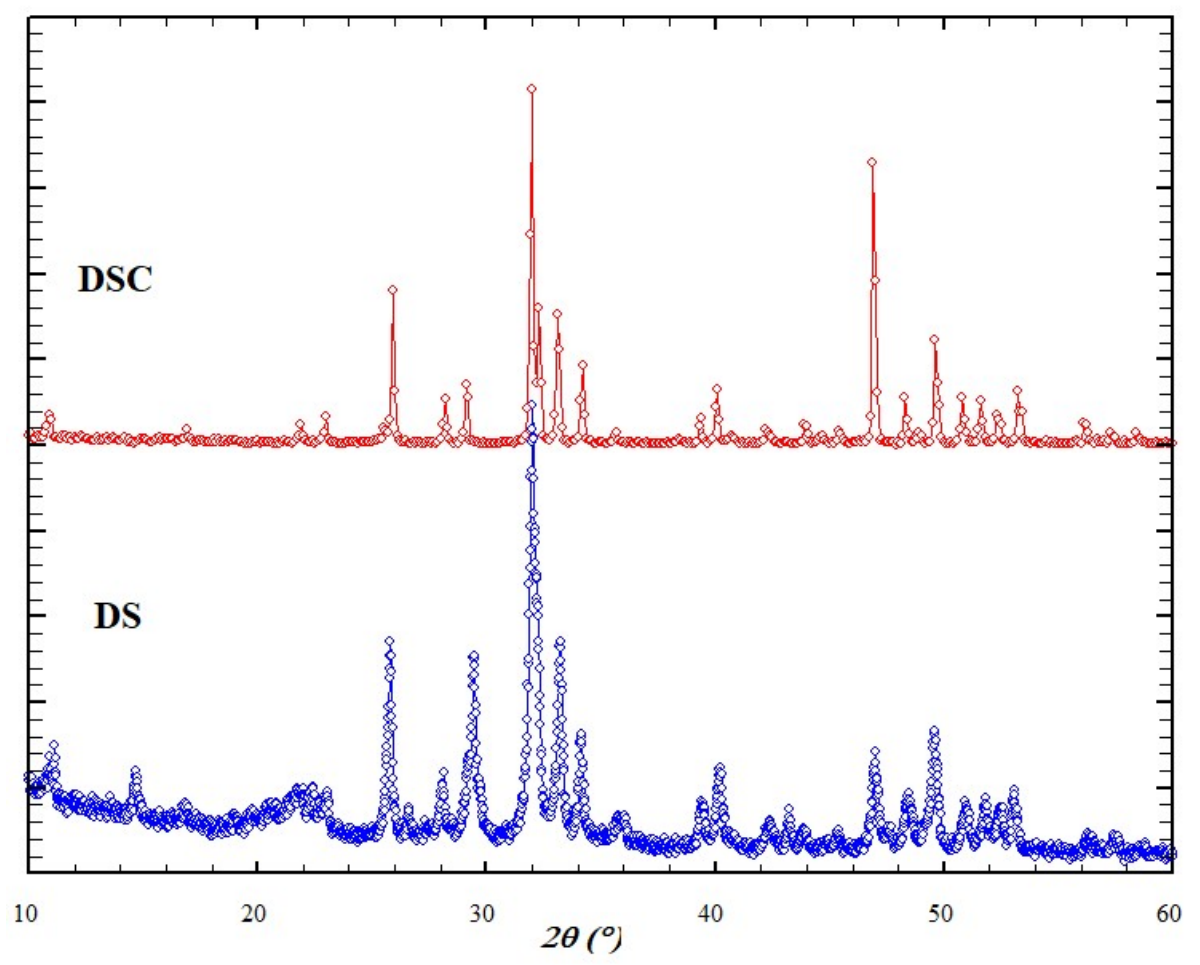

Figure 3. X-ray diagrams of the adsorbents used.

The FTIR spectra of the solid waste are shown in figure 4. The identification of bands was made with reference to similar studies [28-30]. The characteristic bands of the phosphate groups $\mathrm{PO}_{4}$ appearing around $1042 \mathrm{~cm}^{-1}$ was attributed to the symmetrical' valence vibration mode, $v_{1}$. The bands recorded around $1090 \mathrm{~cm}^{-1}$ was related to the antisymmetric valence vibration mode, $v_{3}$. Those between 520 and $570 \mathrm{~cm}^{-1}$ correspond to the antisymmetric mode of deformation, $\mathrm{v}_{4}$, while those located between 400 and $470 \mathrm{~cm}^{-1}$ are associated with the symmetrical mode of deformation, $v_{2}$.

The bands located around 1453-1406 and $863 \mathrm{~cm}^{-1}$ are associated to the $\mathrm{CO}_{3}{ }^{2-}$ group, indicating the presence of these ions in the structure of the materials [31-33]. The two bands around $3450 \mathrm{~cm}^{-1}$ 
and $1640 \mathrm{~cm}^{-1}$ are due to molecular water adsorbed on the surface of the particles [34]. FTIR spectra of the calcined material at $1000{ }^{\circ} \mathrm{C}$ indicated that some chemical changes; the intense peak of the phosphorus group around $1036 \mathrm{~cm}^{-1}$ was shifted to $1081 \mathrm{~cm}^{-1}$. Moreover, the bands linked to carbonate species and impurities have disappeared. The two bands around $3450 \mathrm{~cm}^{-1}$ and $1640 \mathrm{~cm}^{-1}$ are due to molecular water adsorbed on the surface of the particles [35].

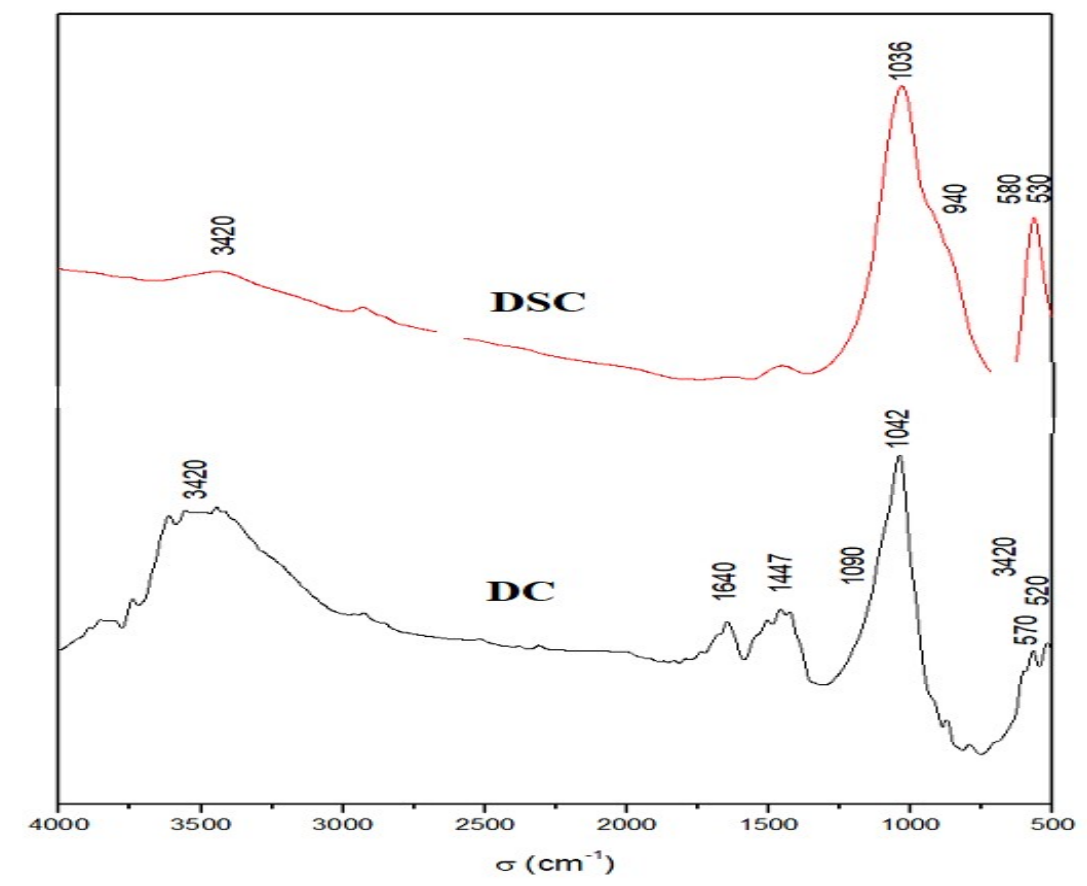

Figure 4. Infrared absorption spectra of the adsorbents used.

The TGA and TDA of the DS samples are shown in figure 5. The curve of the TGA sample displayed three successive weight losses. The first one occurred between room temperature and $150{ }^{\circ} \mathrm{C}$ and is related to water volatilization. The second one is due to the dehydration from 170 to $450{ }^{\circ} \mathrm{C}$ $[28,42]$. The third one, which started at $400{ }^{\circ} \mathrm{C}$ and ended at $1000{ }^{\circ} \mathrm{C}$, was related to the decomposition of carbonates and other materials [42]. The first weight loss is associated with the endothermic effect that is observed on the DTA curve at 85 and $100{ }^{\circ} \mathrm{C}$, with a shoulder at $140{ }^{\circ} \mathrm{C}$. The second weight loss coincides with a broad endothermic effect that is evidenced on the DTA curve at around $350{ }^{\circ} \mathrm{C}$. Concerning the third weight loss, two broad exothermic peaks were observed in the temperature range of $600-1200^{\circ} \mathrm{C}$ and are associated with the phase transformation of some resulting products. The DRX and FTIR data confirmed these weight losses. 


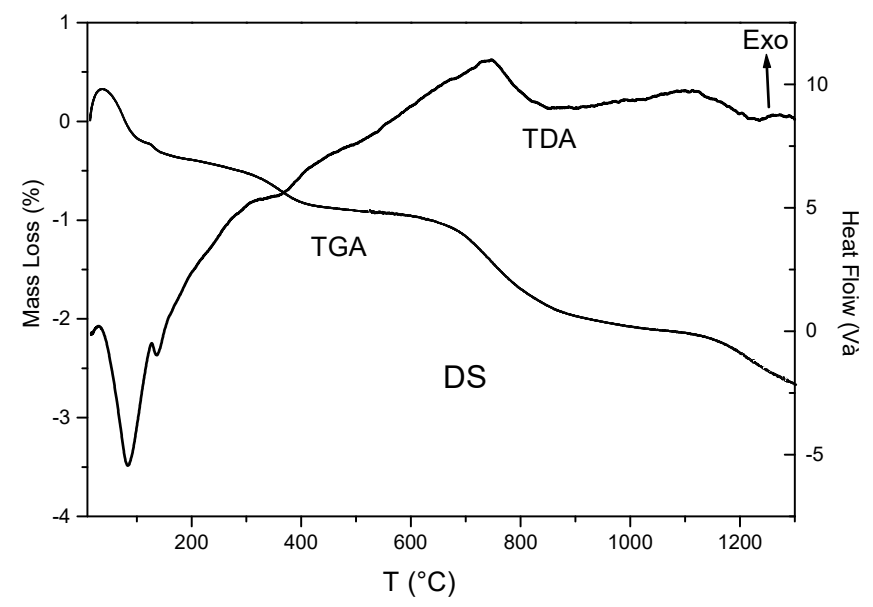

Figure 5. TGA analysis of the natural phosphate (a, a') and phosphate waste rock (b, b') samples

The TDA/TG curves of the DSC sample are shown in Figure 6. For the calcined sample, we noted the presence of a single endothermic peak attributed to the loss of water content.

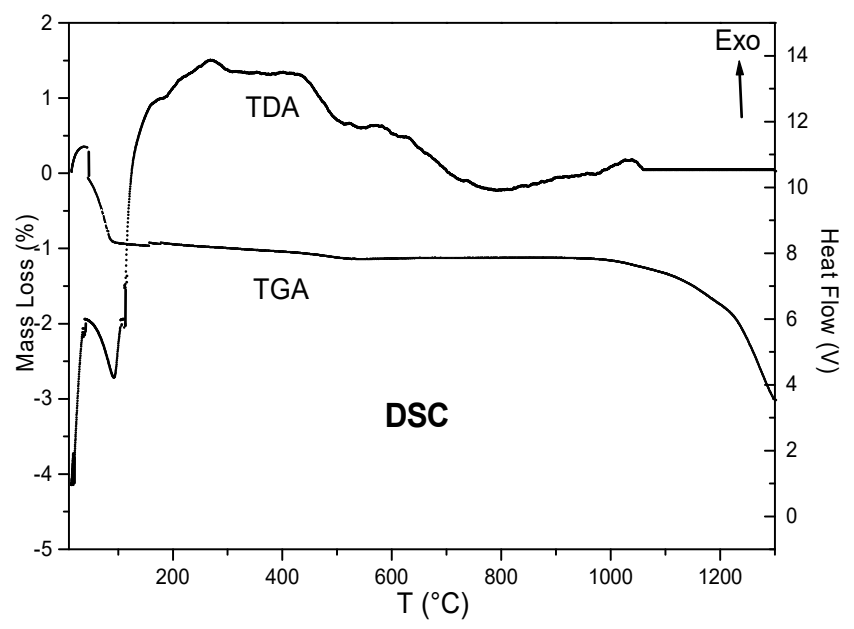

Figure 6. DTA analysis of the natural phosphate $(a, b)$ and phosphate waste rock $(b, b$ ') samples

In the SEM micrographs, the DC and DSC samples show the presence of nonporous particles of different sizes with spherical shapes or ovoid grains. However, in the calcined sample, we observed an improvement of crystallinity, reduced grain size, and an agglomeration of particles (figure 7). 


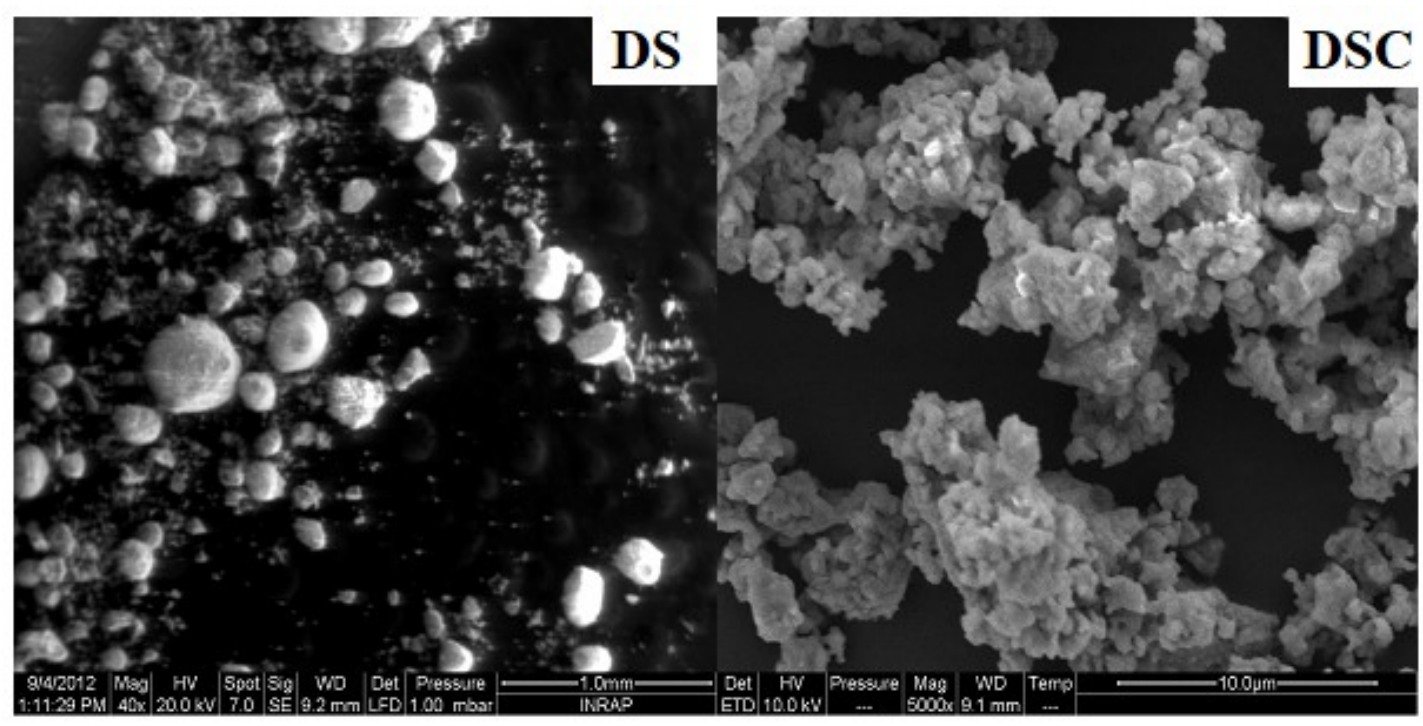

Figure 7. SEM mirographs of DS and DSC samples.

The DS and DSC compounds showed specific surface areas of $26.02 \mathrm{~m}^{2} \cdot \mathrm{g}^{-1}$ and $19.35 \mathrm{~m}^{2} \cdot \mathrm{g}^{-1}$, respectively. These values are near to those measured for natural phosphate rocks [43]. The difference between the two SSA values of both materials could be related to the calcination process allowing the easy insertion of $\mathrm{N}_{2}$ molecules into the adsorbing sites. The average pore volume value increased from 0.052 to $0.041 \mathrm{cc} . \mathrm{g}^{-1}$ after calcination, associated with an average pore diameter of 9.58 and $8.02 \mathrm{~nm}$ for raw and calcined samples, respectively which confirms the nonporous character of the used materials. Upon calcination, a decrease of the surface area values was observed when samples were heated at $1000{ }^{\circ} \mathrm{C}$. These results are, in good agreement with the data described in the literature $[44,45]$. The decrease of the textural properties indicated that the thermal treatment has modified the adsorption sites to $\mathrm{N}_{2}$ molecules compared to the original materials.

\section{2. Effect of adsorbent mass}

Different amounts of adsorbents were introduced into $200 \mathrm{ml}$ of wastewater discharge with a concentration of Acid Red 52 of $100 \mathrm{mg} . \mathrm{L}^{-1}$. The solution was maintained under stirring at a speed of $100 \mathrm{rpm}$ for 4 hours. Figure 8 shows that the removal amount of the dye increased with the increase in the adsorbent quantity. This quantity is related to the nature of the latter. Indeed, $0.15 \mathrm{~g}$ of DS is sufficient to remove almost $99 \%$ of the dye, while it takes $0.35 \mathrm{~g}$ of DSC to achieve the same result. This behavior is related to the increase in adsorption sites on the surface of the particles following the increase in the amount of adsorbent. The better yield, obtained with the DS, can be explained by a finer particle size and a larger specific surface area of the material, and therefore a greater number of adsorption sites. To avoid an adsorbent overdose, it is preferable to work with 
masses less than $0.1 \mathrm{~g}$ of DS and $0.35 \mathrm{~g}$ of DSC. In fact, larger amounts can lead to agglomeration of the powders and to a reduction in their specific surface.

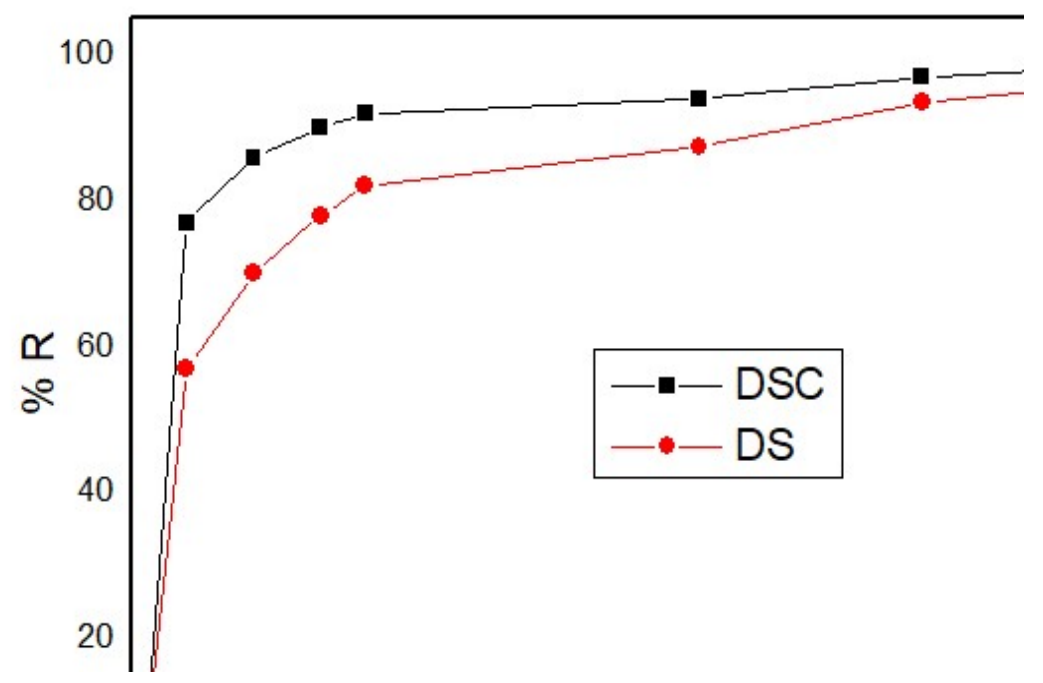

Figure 8. Percentage of Acid Red 52 retained as a function of the mass of the adsorbent

\section{3. pH Effect}

Numerous studies have shown that when studying the adsorption of dyes to different adsorbents, the $\mathrm{pH}$ of solutions is an important factor to be taken into account in any adsorption study [36, 37].

The suspensions used for the study of the influence of $\mathrm{pH}$ were prepared by introducing $0.2 \mathrm{~g}$ of powder into $200 \mathrm{~mL}$ of a solution with a dye concentration of $100 \mathrm{mg} . \mathrm{L}^{-1}$. After adjusting their $\mathrm{pH}$ to between 3 and 9 using a solution of $\mathrm{HCl}$ or $\mathrm{NaOH}(1 \mathrm{M})$ and stirring, the determination of the supernatant was carried out under the same conditions as above.

Figure 9, representing the change in the amount of acid adsorbed as a function of $\mathrm{pH}$, shows that this amount decreases when the $\mathrm{pH}$ of the suspension increases. The dye being acidic, its dissolution in aqueous liberates the anionic ion $\varphi-\mathrm{SO}^{3-}$. As the charge of the adsorbent particles depends on the $\mathrm{pH}$, the increase in the latter is accompanied by an increase in the intensity of the repulsive forces between the anionic fragment of the dye and the surface of the adsorbent particles, which is negatively charged, where the decrease in active sites and in the amounts of adsorbed dye. 


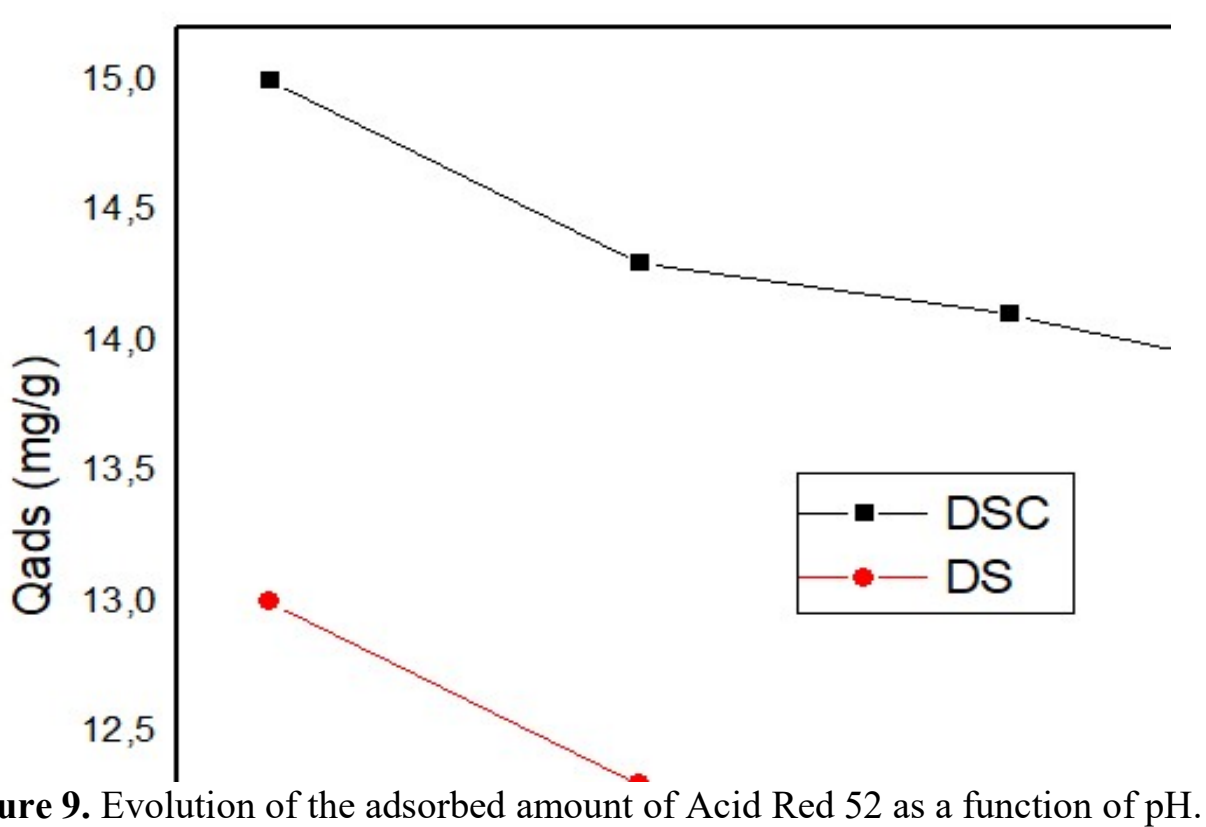

\subsection{Absorption kinetics}

To approximate the mechanism of adsorption of acid red 52 on the materials used, two kinetic models were tested; first order [38] and pseudo second order [39, 40]. These models were chosen for their simplicity and for their application in the field of adsorption of organic compounds on different adsorbents.

\subsubsection{The first order model}

The first order kinetic model is expressed by the following relation:

$$
\frac{\mathrm{dq}_{\mathrm{t}}}{\mathrm{dt}}=\mathrm{k}_{1}\left(\mathrm{q}_{\mathrm{e}}-\mathrm{q}_{\mathrm{t}}\right)
$$

Where qe and qt are respectively the quantity of dye (mg. $\left.\mathrm{g}^{-1}\right)$ fixed on the particles of materials at equilibrium and time $\mathrm{t}$ and $\mathrm{k}_{1}$ is the rate constant $\left(\mathrm{min}^{-1}\right)$. Taking into account the boundary conditions (at $\mathrm{t}=0, \mathrm{q}_{\mathrm{t}}=0$ and at $\mathrm{t}=\mathrm{t}_{\mathrm{e}}, \mathrm{q}_{\mathrm{t}}=\mathrm{q}_{\mathrm{e}}$ ), the integration of the previous relation gives:

$$
\log \left(\mathrm{q}_{\mathrm{e}}-\mathrm{q}_{\mathrm{t}}\right)=\log \mathrm{q}_{\mathrm{e}}-\frac{\mathrm{k}_{\mathrm{l}} \mathrm{t}}{2,3}
$$

The graphical representation of $\log (\mathrm{qe}-\mathrm{qt})$ as a function of $\mathrm{t}$ leads to a line from which the values of $\mathrm{k} 1$ and qe are determined, respectively using the slope and the y-intercept.

\subsubsection{The pseudo second order model}

This model is expressed by the following relation:

$$
\frac{\mathrm{dq}_{\mathrm{t}}}{\mathrm{dt}}=\mathrm{k}_{2}\left(\mathrm{q}_{\mathrm{e}}-\mathrm{q}_{\mathrm{t}}\right)_{2}
$$


$\mathrm{k}_{2}$ is the rate constant.

Integration, taking into account the boundary conditions, gives the following equation: $\frac{\mathrm{t}}{\mathrm{q}_{\mathrm{t}}}=\frac{1}{\mathrm{k}_{2} \mathrm{q}_{\mathrm{e}}^{2}}+\frac{\mathrm{t}}{\mathrm{q}_{\mathrm{e}}}$

The rate constant $\mathrm{k}_{2}$ and the amount of dye fixed at the equilibrium qe are deduced from the curve $^{\frac{t}{q_{t}}}=f(t)$, respectively from the slope and the y-intercept.

The dye fixation kinetics, describing the reaction rate, allows the determination of the contact time necessary to reach the adsorption equilibrium. This study was carried out using suspensions prepared by mixing $200 \mathrm{~mL}$ of a solution of red acid 52 with a concentration of $100 \mathrm{mg} . \mathrm{L}^{-1}$ and 0.2 $\mathrm{g}$ of adsorbent, kept under stirring with a speed of $100 \mathrm{rpm}$. 1 for $400 \mathrm{~min}$.

The results obtained are collated in figure 10. This figure shows that the rate of adsorption is fast at the start of the process and becomes slower over time until equilibrium is achieved. This behavior is to be linked to the decrease in active sites on the surface of the particles of materials, following the attachment of increasingly large quantities of the dye. The times required for the establishment of the absorption equilibrium of the materials are very close and equal to approximately $250 \mathrm{~min}$. It is also noted that the retention capacity of the raw solid waste is greater than that of the calcined solid waste. The quantities used are respectively 14.48 and $11.75 \mathrm{mg} \cdot \mathrm{g}^{-1}$.

The values of the speed constants, deduced from the curves of figures 11 and 12 are grouped together with the values of the adsorbed quantities qe and the regression coefficients $\mathrm{R}^{2}$ in Tables 2 and 3.

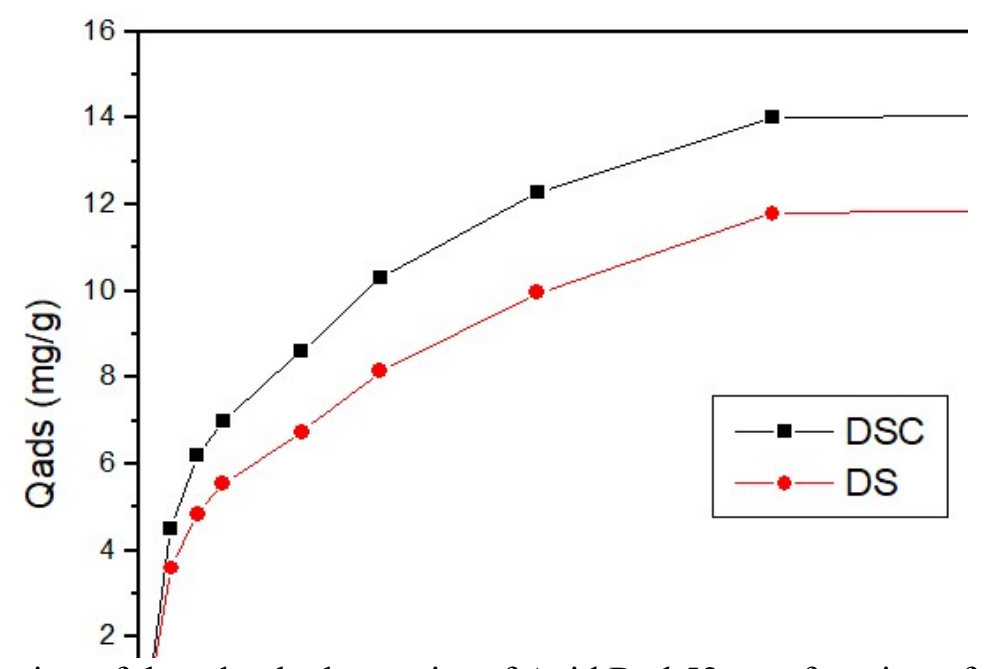

Figure 10. Evolution of the adsorbed quantity of Acid Red 52 as a function of the duration of contact 


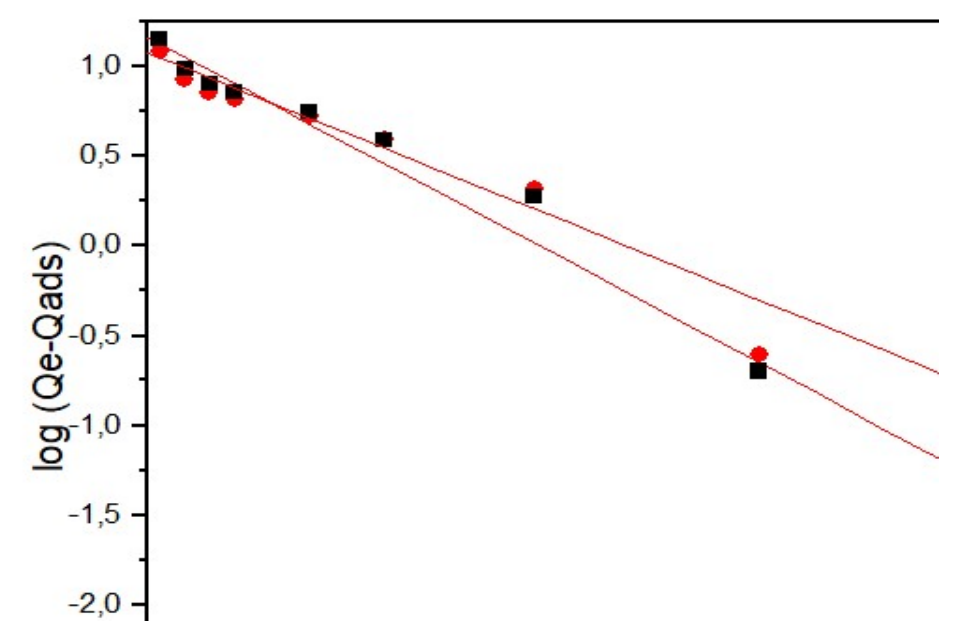

Figure 11. Linear form plot of the second order kinetic model by adsorption of the dye on the DS and DSC

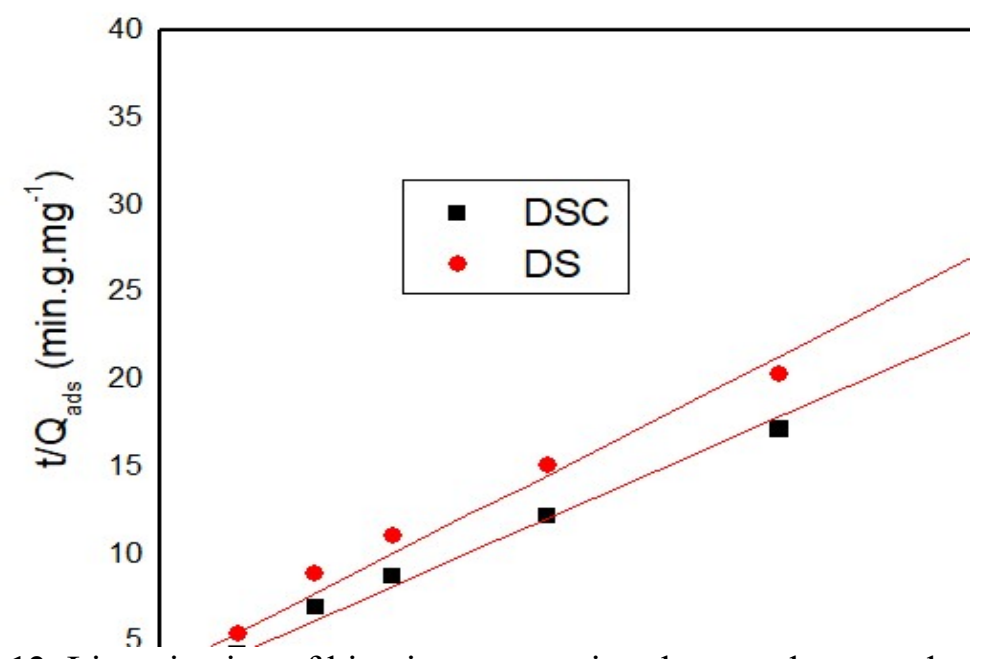

Figure 12. Linearization of kinetic curves using the pseudo second order model.

As these tables show, the values of $\mathrm{R}^{2}$, obtained by applying the first order model are relatively low. On the other hand, those deduced from the pseudo second order model are greater than 0.99. This indicates that the latter model is the most suitable for determining the order of the absorption kinetics of Red Acid 52 on the used materials. In addition, the values of qe calculated using this latter model are close to those determined experimentally, confirming the idea that the absorption kinetics of Red 52 acid by the various adsorbents are of pseudo second order.

Table 2. Kinetic adsorption parameters according to the first order model

\begin{tabular}{lcccc}
\hline & $\mathrm{K}_{\mathrm{v}}\left(\mathrm{min}^{-1}\right)$ & $\begin{array}{c}\mathrm{Q}_{\mathrm{e} \text { théo }} \\
(\mathrm{mg} / \mathrm{g})\end{array}$ & $\begin{array}{c}\mathrm{Q}_{\exp } \\
(\mathrm{mg} / \mathrm{g})\end{array}$ & $\mathrm{R}^{2}$ \\
\hline DS & 0,129 & 14,20 & 11,18 & 0,976 \\
\hline DSP & 0,169 & 12,00 & 13,24 & 0,988 \\
\hline
\end{tabular}


Table 3. Kinetic adsorption parameters according to the pseudo second order model

\begin{tabular}{lcccc}
\hline & $\begin{array}{c}\mathrm{K}^{\prime}\left(\mathrm{min}^{-}\right. \\
\left.\mathrm{gmg}^{-1}\right)\end{array}$ & $\begin{array}{c}\text { Qe théo } \\
(\mathrm{mg} / \mathrm{g})\end{array}$ & $\mathrm{Q}_{\exp }(\mathrm{mg} / \mathrm{g})$ & $\mathrm{R}^{2}$ \\
\hline DS & $1,6910^{-3}$ & 14,200 & 15,41 & 0,998 \\
DSC & $1,7910^{-3}$ & 12,00 & 13,23 & 0,996 \\
\hline
\end{tabular}

\subsection{Adsorption isotherms}

For this study, varying amounts of dye and $0.2 \mathrm{~g}$ of adsorbent were dispersed in distilled water. After stirring at a speed of $100 \mathrm{rpm}$ for $4 \mathrm{~h}$, the measurements were carried out according to the protocol indicated above.

The curves shown in figure 13, show that the quantity of dye fixed on the adsorbents increases rapidly in low concentrations and decreases as the latter increases. It becomes constant near 150 mg. $\mathrm{L}^{-1}$. For this value, there is saturation of the adsorption sites and the equilibrium is reached. Efficiency was significantly reduced from 18.4 to $15.2 \mathrm{mg} \cdot \mathrm{g}^{-1}$ when the sample was heat treated at $1000^{\circ} \mathrm{C}$.

The variation in the removal properties could be related to the changes on the surfaces of the materials obtained with some loss of the groups necessary for the removal of the acid dye. Indeed, it has been reported that the calcination process generally decreases the capacity to remove other solid wastes $[41,42]$.

The modeling of these curves was carried out using the classical models of Langmuir and Freundlich. To develop his model, Langmuir put forward three hypotheses: the adsorption of the adsorbate on the surface of the adsorbent occurs in a single layer, the adsorption takes place at defined sites on the surface of the 'adsorbent, assumed to be uniform and the absence of interactions between the adsorbed molecules [43].

According to this model, at a given temperature, the adsorbed quantity qe is related to the maximum adsorption capacity qm, to the equilibrium concentration $\mathrm{Ce}$ of the adsorbed dye and to the equilibrium constant characteristic of the adsorbent $\mathrm{K}_{\mathrm{L}}$ by the relation

$$
\mathrm{q}_{e}=\frac{\mathrm{q}_{\mathrm{m}} \mathrm{K}_{\mathrm{L}} \mathrm{C}_{\mathrm{e}}}{1+\mathrm{K}_{\mathrm{L}} \mathrm{C}_{\mathrm{e}}}
$$

Whose linear transform is [44]:

$$
\frac{\mathrm{C}_{\mathrm{e}}}{\mathrm{q}_{e}}=\frac{\mathrm{C}_{\mathrm{e}}}{\mathrm{q}_{m}}+\frac{1}{\mathrm{~K}_{\mathrm{Lqm}}}
$$

The values of $\mathrm{qm}$ and $\mathrm{K}_{\mathrm{L}}$ are determined respectively from the intersection with the 
$\mathrm{y}$-axis and the slope of the line $\frac{\mathrm{C}_{\mathrm{e}}}{\mathrm{q}_{e}}=\mathrm{f}(\mathrm{Ce})$.

Unlike Langmuir's, Freundlich's model [45] assumes that adsorption occurs in multilayers, that the surface of the adsorbent is heterogeneous, and that there are interactions between the adsorbed molecules [46]. It is expressed by the following relation:

$$
\mathrm{q}_{\mathrm{e}}=\mathrm{K}_{\mathrm{F}} \mathrm{C}_{\mathrm{e}}^{1 / \mathrm{n}}
$$

Where $\mathrm{K}_{\mathrm{F}}$ is the Freundlich constant $\left(\mathrm{l}^{-1}\right)$ characterizing the adsorbing power of materials and $\mathrm{n}$ is the heterogeneity factor.

The linearization of absorption isotherms according to this model is carried out using the following equation:

$$
\mathrm{Lnq}_{\mathrm{e}}=\ln \mathrm{K}_{\mathrm{F}}+\frac{1}{\mathrm{n}} \ln \mathrm{C}_{\mathrm{e}}
$$

The curves in figure 13 show significant adsorption at low concentrations of the dye. The graphical representation of $\ln (\mathrm{qe})$ as a function of $\ln \left(\mathrm{C}_{\mathrm{e}}\right)$ is a line whose slope is $1 / \mathrm{n}$ and the intercept is $\ln$ $\left(\mathrm{K}_{\mathrm{F}}\right)$

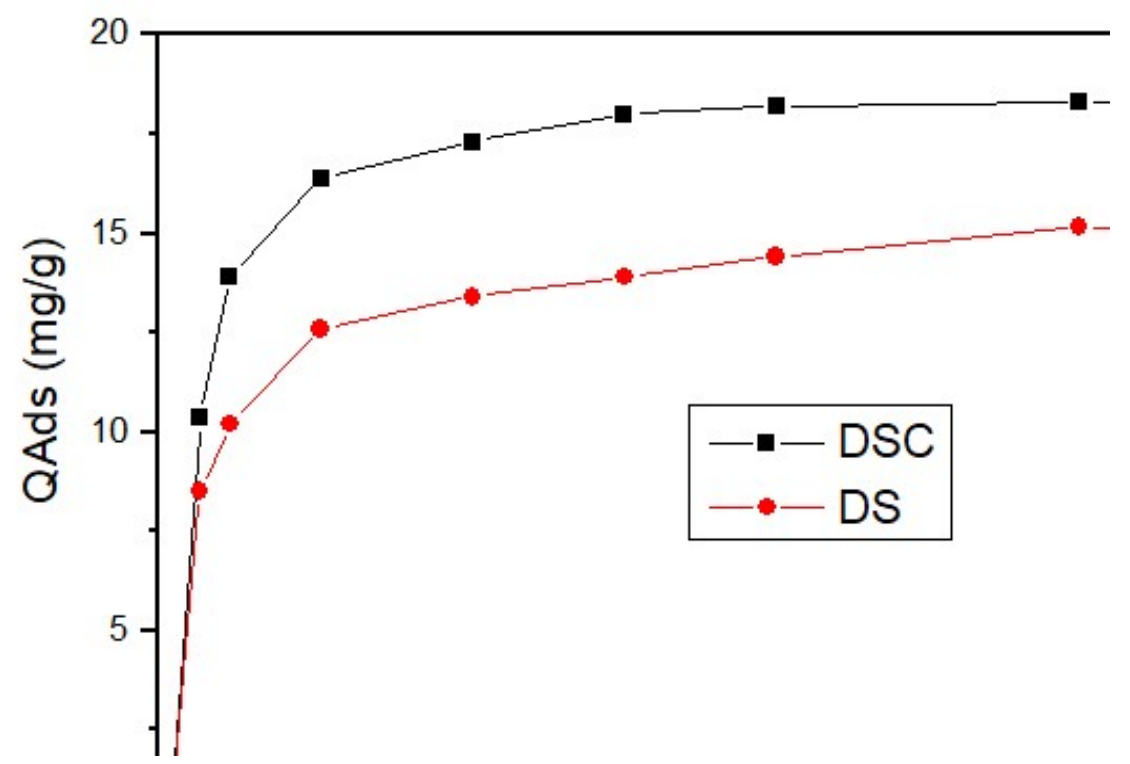

Figure 13. Adsorption isotherms of Acid Red 52.

From figures 14 and 15, it appears that for the two materials, the Langmuir model (figure 14) leads to a good correlation with the experimental results. The linearization of the absorption isotherms of Red Acid 52 on the two samples is perfect, the correlation coefficients are greater than 0.99 (Table 4). 


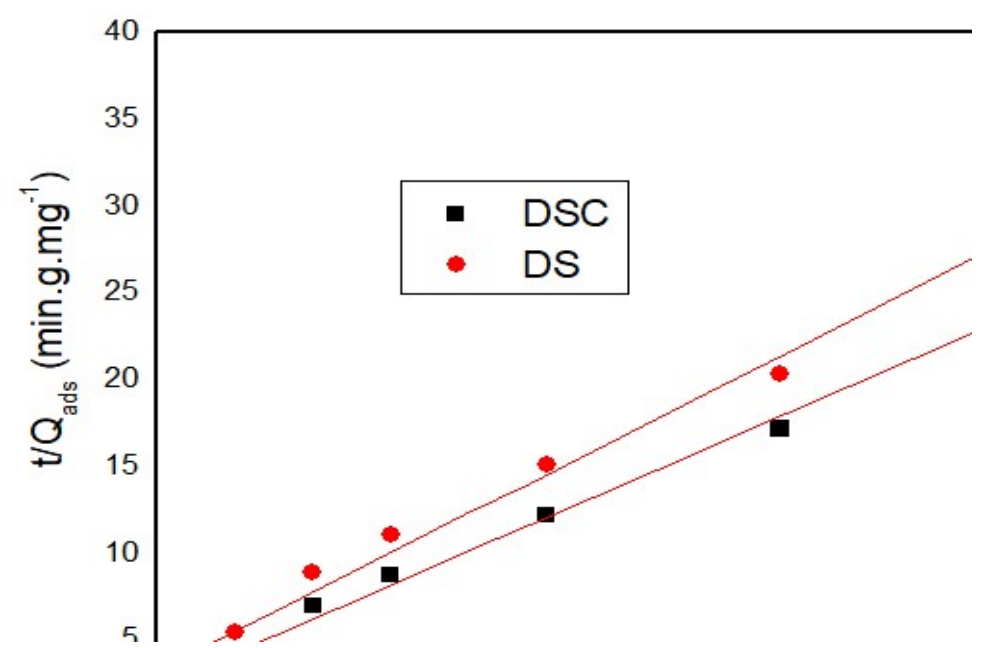

Figure 14. Modeling of adsorption isotherms according to the Langmuir model.

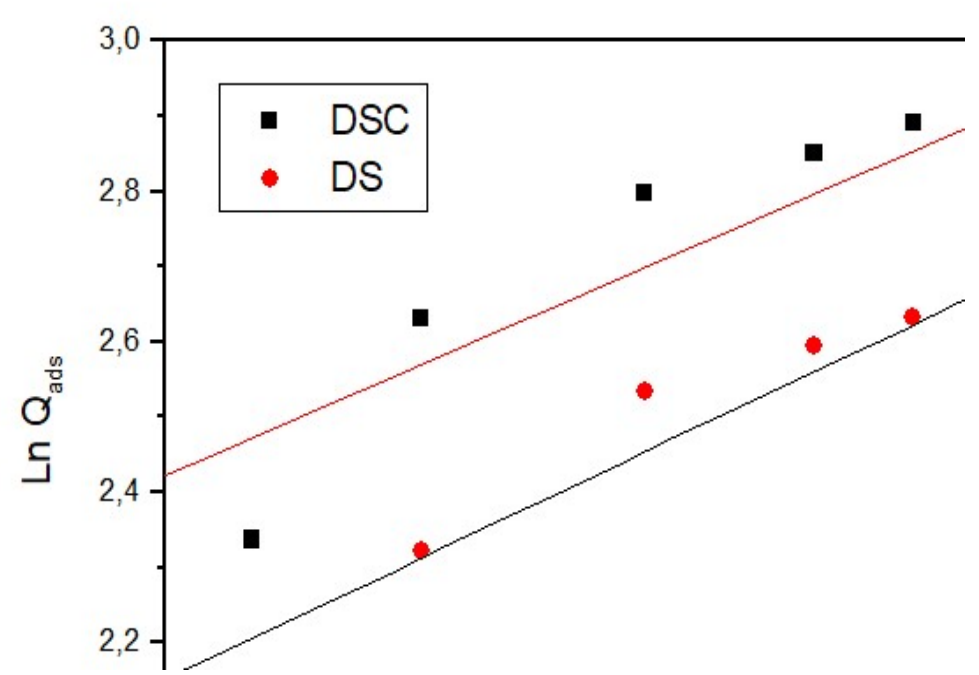

Figure 15. Modeling of adsorption isotherms according to the Freundlich model.

Table 4. Equilibrium parameters according to the Langmuir model

\begin{tabular}{cccc}
\hline Adsorbants & $\mathrm{q}_{\mathrm{m}}(\mathrm{mg} / \mathrm{g})$ & $\mathrm{K}_{\mathrm{L}}\left({\left.\mathrm{L} . \mathrm{g}^{-1}\right)}\right.$ & $\mathrm{R}^{2}$ \\
\hline $\mathrm{DS}$ & 16.732 & 0,272 & 0,999 \\
DSC & 14.615 & 0,155 & 0,999 \\
\hline
\end{tabular}

As expected, the implementation of the Freundlich model leads to low correlation coefficients (Table 5). The values of qm determined by the Langmuir model are given in Table 4, the Freundlich constants Kf and nf are grouped together in Table 6. 
Table 5. Equilibrium parameters according to the Freundlich model

\begin{tabular}{cccc}
\hline Adsorbants & $1 / \mathrm{n}$ & $\mathrm{K}_{\mathrm{f}}\left(\mathrm{L} \cdot \mathrm{g}^{-1}\right)$ & $\mathrm{R}^{2}$ \\
\hline DS & 0,141 & 175,822 & 0,917 \\
DSC & 0,154 & 90,964 & 0,974 \\
\hline
\end{tabular}

\subsection{Temperature effect}

The influence of temperature was studied in the range 35 to $80^{\circ} \mathrm{C}$, using a Mathis type Labomat consisting of 12 bottles. $0.1 \mathrm{~g}$ of each of the two adsorbents was dispersed in $100 \mathrm{~mL}$ of a solution with a dye concentration $100 \mathrm{mg} . \mathrm{L}^{-1}$. Before use, the suspensions were kept under stirring at $40 \mathrm{rpm}^{-1}$ for 1 hour.

Figure 16 is showing the influence of the temperature on the adsorption of acid by different materials, shows that the adsorbed amount decreases with increasing temperature. This decrease suggests that the adsorption process is exothermic.

The thermodynamic quantities $\Delta \mathrm{G}^{\circ}, \Delta \mathrm{H}^{\circ}$ and $\Delta \mathrm{S}^{\circ}$ of the adsorption of the dye on the different adsorbents were determined using the following equations [47, 48]:

$$
\begin{aligned}
& \Delta \mathrm{G}^{\circ}{ }_{\text {ads }}=\Delta \mathrm{H}^{\circ}{ }_{\text {ads }}+\mathrm{T} \Delta \mathrm{S}^{\circ}{ }_{\text {ads }} \\
& \Delta \mathrm{G}^{\circ}{ }_{\text {ads }}=-\mathrm{RT} \ln \mathrm{Kc} \\
& \ln \mathrm{K}_{\mathrm{c}}=\left(\frac{\Delta \mathrm{S}^{\circ}}{\mathrm{R}}\right)-\left(\frac{\Delta \mathrm{H}^{\circ}}{\mathrm{R}}\right) \frac{1}{\mathrm{~T}}
\end{aligned}
$$

with :

$\mathrm{K}_{\mathrm{c}}$ : Distribution coefficient of the dye between the adsorbent and the solution

$\mathrm{R}$ : Ideal gas constant $\left(\mathrm{J} \cdot \mathrm{mol}^{-1} \cdot \mathrm{K}^{-1}\right)$

$\mathrm{T}$ : Absolute temperature $(\mathrm{K})$. 


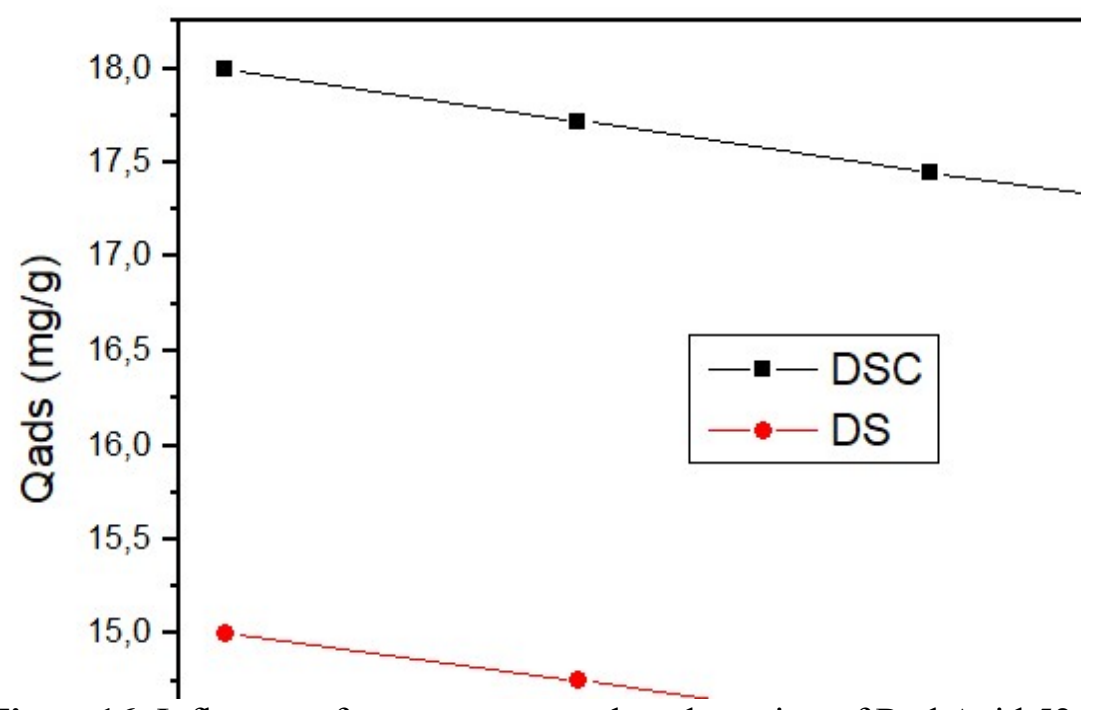

Figure16. Influence of temperature on the adsorption of Red Acid 52

By taking $\operatorname{lnKc}$ as a function of $1 / T$, we obtain a line with the $y$-intercept $\frac{\Delta S^{\circ}}{R}$ and slope $\frac{-\Delta \mathrm{H}^{\circ}}{\mathrm{R}}$ (figure 17).

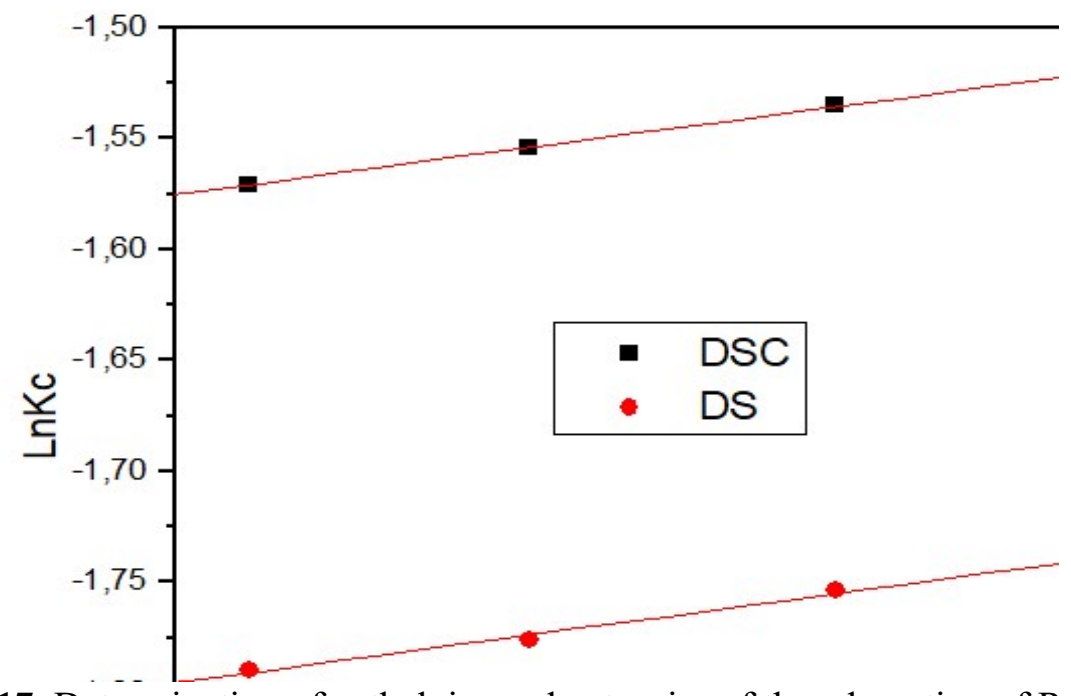

Figure 17. Determination of enthalpies and entropies of the adsorption of Red Acid 52.

The results obtained are grouped in Table 6. The negative values of the three quantities $\Delta \mathrm{G}^{\circ}$, $\Delta \mathrm{H}^{\circ}$ and $\Delta \mathrm{S}^{\circ}$ indicate that the adsorption of red acid on the various adsorbents is spontaneous, exothermic and that the order of distribution of the molecules of the dye on the adsorbent is greater than that in the solution $[49,50]$. Furthermore, the $\Delta \mathrm{H}^{\circ}$ values obtained for DS and DSC of the order of $1 \mathrm{~kJ} . \mathrm{mol}-1$ ) are in favor of physisorption. 
Table 6. Thermodynamic adsorption parameters

\begin{tabular}{cccc}
\hline Adsorbants & $\Delta \mathrm{H}^{\circ}\left(\mathrm{kJ} \cdot \mathrm{mol}^{-1}\right)$ & $\Delta \mathrm{S}^{\circ}\left(\mathrm{J} . \mathrm{K} \cdot \mathrm{mol}^{-1}\right)$ & $\mathrm{R}^{2}$ \\
\hline DS & $-1,10$ & $-16,20$ & 0,999 \\
DSC & $-1,13$ & $-18,08$ & 0,998 \\
\hline
\end{tabular}

The increase in $\Delta \mathrm{G}^{0}$ values with temperature is related to the increase in disorder during adsorption (Table 7).

Table 7. Standard free enthalpy of adsorption

\begin{tabular}{cccccc}
\hline$\Delta \mathrm{G}^{\circ}\left(\mathrm{kJ} \cdot \mathrm{mol}^{-1}\right)$ & & & & & \\
\hline & $\mathrm{T}$ & 308 & 323 & 338 & 353 \\
& $(\mathrm{~K})$ & & & & \\
\hline Adsorbants & $\mathrm{DS}$ & $-6,09$ & $-6,33$ & $-6,57$ & $-6,81$ \\
& $\mathrm{DSC}$ & $-6,70$ & $-6,97$ & $-7,24$ & $-7,51$ \\
\hline
\end{tabular}

\section{Conclusion}

The solid wastes of the phosphate industry resulting from the washing of rock phosphate, studied in this work, are found in abundance in Tunisia country and are free, in addition to their inconvenient of expensive storage.

The carried out study shows that it is possible to recover these harmful materials in the de-pollution of waste water from the textile industry, loaded with dyes. Indeed, the tests revealed that Red Acid 52 has been successfully retained on the solid waste of the phosphate industry used. The results obtained also indicated that the solid waste from washing the uncalcined rock phosphate has the best adsorption capacity $18.4 \mathrm{mg} \cdot \mathrm{g}^{-1}$. The retained quantity decreases when the adsorbent is calcined. The most appropriate model to understand the experimental results of the adsorption kinetics on the two adsorbents is the pseudo second order model. As for the adsorption isotherms, they are well described by the Langmuir model.

The study of the effect of temperature on the adsorption of 52 acid by solid waste from washing of calcined and uncalcined rock phosphate, shows a decrease in the amount adsorbed with increasing temperature. Furthermore, the determination of the thermodynamic quantities shows that the adsorption is spontaneous and exothermic. The values of the enthalpy of adsorption indicate that this reaction is physical in nature for both materials. 


\section{References :}

1. Rossner A., Snyder S.A., Knappe D.R.U., Water Res. 2009, 43, 3787.

2. Venkata Mohan S., Sailaja P., Srimurali M., Karthikeyan J., Environ. Eng. Policy 1999, 1, 149.

3. Shin H.S., Lee J.K., Korean, J. Chem. Eng. 2006, 23(2) 188.

4. Crini G., Bioresource Technol. 2006, 97, 106.

5. Muthukumar M., Sargunamani D., Selvakumar N., Dyes Pigments 2005, 65, 151.

6. Muthukumar M., Sargunamani D., Senthilkumar M., Selvakumar N., Dyes Pigments 2005, 64, 39.

7. Khehra M.S., Saini H.S.,. Sharma D.K, Chadha B.S., Chimni S.S. Dyes Pigments 2006, 701.

8. O’Neill C., Lopez A., Esteves S., Hawkes F.R., Hawkes D.L., Wilcox S.. Appl. Microbiol. Biot. 2000, 53(2) 249.

9. Sharma D.K., Saini H.S., Singh M., Chimni S.S., Chadha B.S., Lett. Appl. Microbiol. 2004, 38, 345.

10. El-Geundi M.S., Water Res. 1991, 25271.

11. Nassar M.M., Hamoda M.F., Radwan G.H., Water Sci. Technol. 1995, 32, 27.

12. Nassar M.M., Magdy Y.H., Chem. Eng. J. 1997, 66223.

13. Nassar M.M., Water Sci. Technol. 1999, 40, 133.

14. Morais L.C., Freitas O.M., Gon calves E.P., Vasconcelos L.T., Gonzalez C.G., Water Res. 1999, 33, 979.

15. Robinson T., Chandrai B., Nigam P., Water Res. 2002, 36, 2824.

16. Padmesh T.V.N., K. Vijayaraghavan, Sekaran G., Velan M., Chem. Eng. J. 2006,122, 55.

17. Gupta V.K., Mohan D., Sharma S., Sharma M., Separ. Sci. Technol. 2000,35, 2097.

18. Liversidge R.M., Lloyd G.J., Wase D. A. J.. C. Forster F., Process Biochem. 1997, 32473.

19. Robinson T., Chandran B., Nigam P., Environ. Int. 2002, 28, 29.

20. Ann adurai G., Juang R.-S., Lee, J. Hazard D.J.. Mater. 2002, B 92, 263.

21. Sivaraj R., Namasivayam C., Kadirvelu K., Waste Manage. (Oxford) 2001, 21, 105.

22. Raïs Z., El Hassani L., Maghnouje J., Hadji M., Ibnelkhayat R., Nejjar R., Kherbeche A.

Chaqroune A., Phys. Chem. News 2002, 7, 100.

23. Barka N., Assabbane A., Nounah A., Laanab L., Aît Ichou Y., Desalination 235 (2009) 264.

24. Achkoun A., Naja J., and'Hamdi R. M., J. Chem. Chem. Eng. 2012, 6, 721.

25. Jha P., Jobby R.,N. Desai S, J. Hazard. Mater. 2016, 311, 158.

26. Hussain G., Ather M., Ul Ain Khan M., Saeed A., Saleem R., Shabir G, Ali Channar P. Dyes Pigments 2005, 65, 151. 
27. Mizane A. and Louhi A., Calcination effects on sulfuric dissolution of phosphate extracted from djebel onk mine (Algeria), Asian J. Chem. 2008, 20, 711-717

28. Elliott J. C., Structure and chemistry of the apatites and other calcium orthophosphates, Elsevier, Amsterdam 1994.

29. Raynaud S., Champion E., Bernache-Assollant D., Thomas P., Biomaterials 2002, 23, 1065.

30. El Hammari L., Merroun H., Coradin T., Laghzizil A., Barboux P., Saoiabi A., Mater. Chem. Phys. 2007, 104, 448.

31. E. Feki H., Savariault J.M., Ben Salah A., J. Alloys Compd 1999, 287, 114.

32. Lafon J. P., Champion E., Bernache-Assollant D., J. Eur. Ceram. Soc. 2008, 28, 139.

33. Gmati N., Boughzala K., Abdellaoui M., Bouzouita K., C. R. Chimie 2011, 14 ,896.

34. Elliott J. C. The crystallographic structure of dental enamel and related apatites. PhD Thesis, University of London 1994.

35. Elliott J. C. The crystallographic structure of dental enamel and related apatites. PhD Thesis, University of London 1994.

36. El Boujaady H., El Rhilassi A., Bennani-Ziatni M., El Hamri R., Taitai A. and Lacout J.L., Removal of a textile dye by adsorption on synthetic calcium phosphates, Desalination, 2011, 275, 10-16.

37. Kooli F., Yan L., Al-Faze R. and Al Suhaimi A., Effect of acid activation of Saudi local clay mineral on removal properties of basic blue 41 from an aqueous solution, Applied Clay Sci., 2015, 116-117, 23-30.

38. Lagergren S., Vetenskapsakad S., Hand. Band. 1898, 24 (4), 1.

39. Ho Y.S., Mc Kay G., Water Res. 2000, 34 (3), 735.

40. Ho Y.S., Mc Kay G., Process Biochem. 1996, 34, 451.

41. Vimonses V., Jin B., Chow C.W.K. and Saint C., Enhancing removal efficiency of anionic dye by combination and calcination of clay materials and calcium hydroxide, $\mathrm{J}$. Hazrd. Mater.. 2009, 171, 941-947.

42. Graba Z., Hamoudi S., Bekka D., Bezzi N. and Boukherroub R., Influence of adsorption parameters of basic red dye 46 by the rough and treated Algerian natural phosphates, J. Ind Eng. Chem., 2015, 25, 229-238.

43. Langmuir L., J. Am. Chem. Soc. 1918, 40, 1361.

44. Stumm W., Morgan J.J., Aquatic chemistry, Ed.2, Wiley inter-science J., Wiley \& sons 1981. 45. Freundlich H., Colloid and Capillary Chemistry, Metheum, London, 1926.

46. Mc Kay G., Use of Adsorbents for the Removal of Pollutants From Wastewaters, CRC Press, 1996. 
47. Abd El-Rahman K.M., El-Kamash A.M., El-Sourougy M.R., Abdel-Moniem N.M., J. Radioanal. Nucl. Ch. 2006, 268, 221.

48. Demirbas A., Sari A., Isildak O., Hazard J.. Mater. 2006, B135, 226.

49. Rytwo G., Ruiz-Hitzky E., J. Therm. Anal. Calorim. 2003, 71, 751.

50. Ramesh A., Lee D.J., Wong J.W., J. Colloid. Interf. Sci. 2005, 291, 588. 